\title{
Anterior temporal lobectomy versus selective amygdalohippocampectomy in patients with mesial temporal lobe epilepsy
}

\author{
Lobectomia temporal anterior versus amigdalohipocampectomia seletiva para epilepsia \\ de lobo temporal mesial
}

\author{
Fábio A. Nascimento', Luana Antunes Maranha Gatto², Carlos Silvado³, Maria Joana Mäder-Joaquim4, \\ Marlus Sidney Moro², Joao Candido Araujo²
}

\begin{abstract}
Objective: To contribute our experience with surgical treatment of patients with mesial temporal lobe epilepsy (mTLE) undergoing anterior temporal lobectomy (ATL) or selective amygdalohippocampectomy (SelAH). Method: This is a retrospective observational study. The sample included patients with medically refractory mTLE due to unilateral mesial temporal sclerosis who underwent either ATL or SelAH, at Hospital de Clinicas - UFPR, from 2005 to 2012. We report seizure outcomes, using Engel classification, cognitive outcomes, using measurements of verbal and visuospatial memories, as well as operative complications. Result: Sixty-seven patients (33 ATL, 34 SelAH) were studied; median follow-up was 64 months. There was no statistically significant difference in seizure or neuropsychological outcomes, although verbal memory was more negatively affected in ATL operations on patients' dominant hemispheres. Higher number of major complications was observed in the ATL group ( $p=0.004)$. Conclusion: Seizure and neuropsychological outcomes did not differ. ATL appeared to be associated with higher risk of complications.
\end{abstract}

Keywords: temporal lobe epilepsy, amygdalo-hippocampal epilepsy, anterior temporal lobectomy, neuropsychological tests, seizures, postoperative complications.

\section{RESUMO}

Objetivo: Contribuir com nossa experiência para o tratamento cirúrgico de pacientes com epilepsia do lobo temporal mesial submetidos a lobectomia temporal anterior (LTA) ou amigdalohipocampectomia seletiva (AHS). Método: Estudo retrospectivo observacional. Foram incluídos pacientes com epilepsia refratária devido a esclerose mesial temporal unilateral, submetidos a LTA ou AHS no Hospital de Clínicas - UFPR, entre 2005-2012. Foram comparados os resultados cognitivos (análises de memórias verbal e visuoespacial), controle de crises (Engel) e complicações cirúrgicas. Resultados: Sessenta e sete pacientes (33 LTA, 34 AHS) foram estudados; o período de acompanhamento médio foi de 64 meses. Não houve diferença no controle das crises ou resultado neuropsicológico, mas a memória verbal foi mais negativamente afetada nos pacientes submetidos à LTA no hemisfério dominante. Maior número de complicações graves ocorreu no grupo de LTA ( $p=0.004)$. Conclusão: Controle de crises e resultados neuropsicológicos não diferiram. LTA pareceu estar associada a um maior risco cirúrgico.

Palavras-chave: epilepsia do lobo temporal, epilepsia amígdalo-hipocampal, lobectomia temporal anterior, testes neuropsicológicos, crises convulsivas, complicações pós-operatórias.

It is estimated that one third of patients with seizures have medically intractable epilepsy (MIE) - defined as failure of two antiepileptic medications given at appropriate doses ${ }^{1,2}$. Temporal lobe epilepsy (TLE) is the most common form of MIE. The most frequent pathologic substrate related to this condition is sclerosis and atrophy of the hippocampus - disease named mesial temporal sclerosis (MTS) ${ }^{3}$. Presently, there are multiple approaches to resection of TLE; the most common being the standard anterior temporal lobectomy (ATL) and selective amygdalohippocampectomy

'University of Toronto, Toronto Western Hospital, Division of Neurology, Toronto, Ontario, Canada;

¿Universidade Federal do Paraná, Hospital de Clinicas, Departamento de Neurocirurgia, Curitiba PR, Brazil;

${ }^{3}$ Universidade Federal do Paraná, Hospital de Clinicas, Departamento de Neurologia, Serviço de Epilepsia e Eletroencefalograma, Curitiba PR, Brazil;

«Universidade Federal do Paraná, Hospital de Clinicas, Departamento de Neurologia, Curitiba PR, Brazil.

Correpondence: Fábio Augusto Nascimento e Silva; 5W-445; 399, Bathurst St. M5T 2S8; Toronto, Ontario, Canada; E-mail: nascimento.fabio.a@gmail.com

Conflict of interest: There is no conflict of interest to declare.

Received 25 May 2015; Received in final form 31 August 2015; Accepted 22 September 2015. 
(SelAH). In general, and regardless of the subtype of surgical approach, patients with MTS achieve postoperative seizure freedom in $59-89 \%$ of the times ${ }^{4}$. Studies have been focusing on the comparison of the two procedures, in terms of seizure and/or neurocognitive outcome, although a consensus is far from being reached.

In this context, this study contributes the Hospital de Clínicas - UFPR experience, as a reference hospital in Brazil, for the treatment of epilepsy. This is a retrospective observational study assessing seizure and neurocognitive outcomes, as well as postoperative complications, in patients diagnosed with MTS who were submitted to either ATL or SelAH at the Hospital de Clínicas from 2005 and 2012.

\section{METHOD}

\section{Subjects}

This is a retrospective observational study. Patients with medically refractory TLE due to unilateral MTS who underwent resective surgical therapy (either ATL or SelAH) at Hospital de Clínicas - UFPR from 2005 to 2012 were included. Data was collected by chart review. The study was approved by the local regulatory board. Informed consent was obtained from every individual involved in this research.

A total of 212 patients diagnosed with medically refractory MTS were submitted to resective surgery at our centre. Of these, sixty-seven met the inclusion criteria and were, included in this study (33 ATL; 34 SelAH). Median follow-up was 64 months. For the interest of statistical convenience, we analysed only the data up to the fifth year of follow-up. Demographic and clinical features of the patients can be seen at Table 1. Both groups were well matched as depicted in Table 1; therefore, these groups can be defined as being epidemiologically homogenous.

All patients had pre-surgical workup including video-EEG long-term monitoring, magnetic resonance imaging (MRI), and neuropsychological evaluation - if required, we performed additional tests such as invasive EEG, Wada test, SPECT and/or PET-CT -, as well as postoperative neuropsychological testing, and at least two years of follow-up after surgery. The exclusion criteria were as follows: (1) age less than 14 years, and (2) severe cognitive delay or mental retardation (these would not be able to be assessed by the same neuropsychological tests, what would preclude a reliable singular comparison).

Selection of patients to this study was not influenced by genre, ethnicity, social/economical/cultural status, or comorbidities - including psychiatric disorders (such as depression, psychosis, and anxiety), since these conditions are frequently concomitant in patients with $\mathrm{TLE}^{5}$.

\section{Surgical approach}

As part of the teaching hospital Hospital de Clínicas - UFPR, our Epilepsy Surgical Program has two attending neurosurgeons that alternate weekly. One surgeon systematically uses the ATL approach, whereas the other systematically uses the SelAH approach. Patients were assigned to a surgeon, and consequently a surgical approach based on which week the operation was booked for. Therefore, a reliable comparison between the outcomes of the two surgical approaches is permitted because the patient distribution can be considered as random and the two groups can be considered as homogenous.

\section{Operative techniques (ATL and SelAH)}

Surgical treatment for TLE secondary to MTS aims to remove mesial temporal structures. Partial resection (approximately $3 \mathrm{~cm}$ in length) of the hippocampus, amygdala, and parahippocampal gyrus is performed, followed by total resection of the uncus.

In the ATL approach, the resection involves, in addition to the mesial structures, the superficial neocortical temporal gyri. These gyri should be removed even if they are not known to be epileptogenic, based on the observation that these structures (despite being healthy) would propagate seizure activity from temporal mesial sites ${ }^{6}$. Since more tissue is resected, some experts argue that the ATL technique confers higher chances of medium/long-term seizure control (Figures 1 and 2).

The SelAH technique, on the other hand, spares the neocortical gyri. Concerning the possible accesses, through which the resection of the hippocampus and adjacent structures is performed, they can be transsylvian, transinsular, subtemporal, or transcortical - via white matter on the middle temporal gyrus. The latter is the most used worldwide - and also at our service -, due to lower operative risks. The rationale behind choosing the SelAH remains on the fact that the main origin of epileptogenic activity lies on the mesial portion of the temporal lobe; therefore, additional resection of superficial cortex would not influence on seizure control 7 . Moreover, this technique, for sparing the temporal neocortex, in theory results in less postoperative cognition deficits (including memory, language, and behaviour) (Figures 3, 4, and 5).

\section{Complications}

Recent systematic review on complications of epilepsy surgery proposed a slightly different classification of operative complications ${ }^{8}$. According to this study, minor complications would be the ones that resolved within three months after surgical intervention, whereas major complications are those that persisted beyond this period of time. Although this classification has been frequently used by other researchers ${ }^{9}$, we believe it would not be suitable for this study, given that it rates events exclusively by their duration.

According to our proposal, major complications are considered all those that prolong the Intensive Care Unit admission period after resection, lead to the need to redo urgent surgical 


\begin{tabular}{|c|c|c|c|c|}
\hline & SelAH $(n=34) n(\%)$ & $\operatorname{ATL}(n=33) \mathrm{n}(\%)$ & $p$-value & Total \\
\hline \multicolumn{5}{|l|}{ Gender } \\
\hline Female & $14(41.18)$ & $16(48.48)$ & 0.627 & 30 \\
\hline Male & $20(58.82)$ & $17(51.52)$ & & 37 \\
\hline Age at surgery $(\varnothing)$ & 33.4 & 37.6 & 0.136 & 35.46 \\
\hline Age at first seizure $(\varnothing)$ & 8.3 & 10.2 & 0.286 & 9.23 \\
\hline Duration of epilepsy $(\varnothing)$ & 25.4 & 27.4 & 0.552 & 26.38 \\
\hline \multicolumn{5}{|l|}{ Side of resection } \\
\hline Nondominant & $15(44.12)$ & $18(54.55)$ & 0.467 & 33 \\
\hline Dominant & $19(55.88)$ & $15(45.45)$ & & 34 \\
\hline \multicolumn{5}{|l|}{ Handedness } \\
\hline Right & $30(88.24)$ & $30(90.91)$ & 1 & 60 \\
\hline Left & $3(8.82)$ & $2(6.06)$ & & 5 \\
\hline Ambidextrous & $1(2.94)$ & $1(3.03)$ & & 2 \\
\hline Education level $(\varnothing)$ & 8.2 & 8 & 0.778 & 8.1 \\
\hline Systemic comorbidities & 6 & 11 & - & 17 \\
\hline History of CNS infection & 2 & 2 & - & 4 \\
\hline History of severe head trauma & 2 & 2 & - & 4 \\
\hline Family history of epilepsy & $2(5.88)$ & $1(3.13)$ & 1 & 3 \\
\hline \multicolumn{5}{|c|}{ Additional presurgical workup needed } \\
\hline Wada test & $3(8.82)$ & $1(3.03)$ & 0.614 & 4 \\
\hline PET-CT & $1(2.94)$ & $3(9.09)$ & 0.356 & 4 \\
\hline SPECT & $2(5.88)$ & $1(3.03)$ & 1 & 3 \\
\hline Sphenoidal EEG & $1(2.94)$ & $3(9.09)$ & 0.288 & 4 \\
\hline \multicolumn{5}{|l|}{ Number of AEDs at time of surgery } \\
\hline 1 & $3(8.82)$ & $3(9.09)$ & 0.585 & 6 \\
\hline 2 & $11(32.35)$ & $9(27.27)$ & & 20 \\
\hline 3 & $15(44.12)$ & $19(57.58)$ & & 34 \\
\hline 4 & $5(14.71)$ & $2(6.06)$ & & 7 \\
\hline \multicolumn{5}{|l|}{ Histopathology } \\
\hline Mesial sclerosis & 15 & 29 & & 44 \\
\hline Normal & 1 & 2 & & 3 \\
\hline Not performed. Aspiration only & 19 & 1 & & 20 \\
\hline Hemorrhage only & 0 & 1 & & 1 \\
\hline Admission period (days) & 8.7 & 11.5 & 0.537 & 10 \\
\hline
\end{tabular}

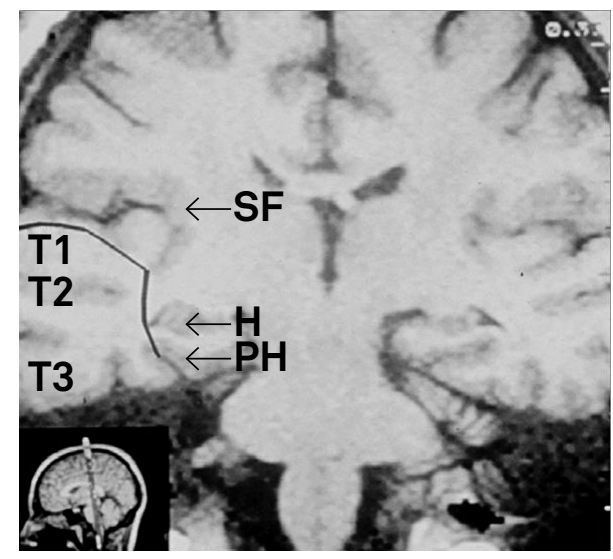

T1-weighted coronal MRI; resection is demarcated with gray-colored line. ATL: anterior temporal lobectomy; $\mathrm{H}$ : hippocampus; $\mathrm{PH}$ : parahippocampal gyrus; T1,T2 e T3: superior, middle, and inferior temporal gyri; SF: Sylvian fissure.

Figure 1. Temporal resection in the ATL approach.

procedure, as well as increase the risk of death (lethal potential). With this definition, all major vascular accidents, as well as severe infections, are considered major postoperative complications. Complications that do not fit the above-mentioned criteria are classified as minor. In terms of neurological deficits after procedure, we divided them into two groups, transitory and permanent, based on a 3-month cut off (transitory if the deficit resolves completely before 3 months postoperatively; permanent if it does not resolve by the $3^{\text {rd }}$ month).

\section{Neuropsychological testing}

All patients were evaluated prior to and at least 6 months following surgery. Individuals with severe cognitive delay or mental retardation - due to the impossibility of them being assessed by standard neuropsychological tests -, as well as those who were not tested post-operatively, were excluded.

The neuropsychological protocol used by our center's Epilepsy Service investigates visuospatial and verbal memories. The former was evaluated by the Rey-Osterrieth Complex Figure Test (ROCF). The parameter of most importance for this study, provided by the ROCF test, was our patients' delayed recall ability. The verbal memory was evaluated by the Rey Auditory Verbal Learning Test (RAVL). From this test's results, we could measure our patients' long-term verbal memory. 
Longitudinal neuropsychological evolution (in terms of verbal and visuospatial memories), prior and after surgery, was analysed using both (a) raw psychometric data and (b)

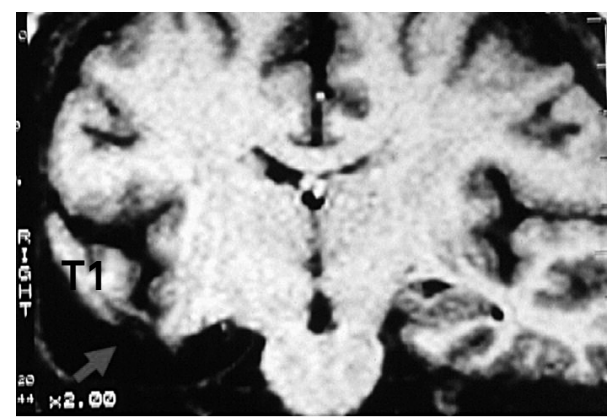

T1-weighted coronal MRI; grey arrow targets the site of status-post right ATL. $\mathrm{T} 2, \mathrm{~T} 3$, hippocampus, and parahippocampal gyrus were resected; amygdala was partially removed. ATL: anterior temporal lobectomy.

Figure 2. ATL, postoperative MRI.

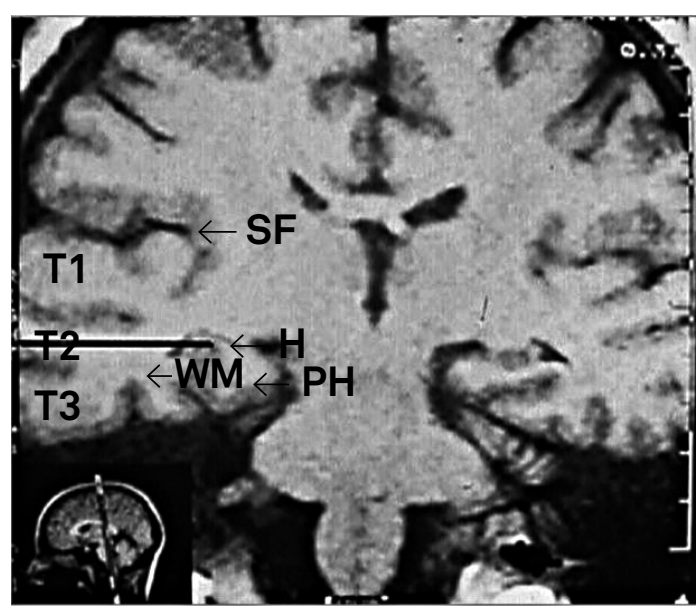

T1-weighted coronal MRI. The black line corresponds to the corridor of dissection (with a $3 \mathrm{~cm}$ incision) through T2 to the mesial structures. SelAH: selective amygdalohippocampectomy; WM: white matter; H: hippocampus; PH: parahippocampal gyrus. T1, T2 e T3: superior, middle, and inferior temporal gyri;SF:Sylvian fissure.

Figure 3. Transcortical access in the SelAH approach.
Z-scores. The first method (a) considered cognitive improvement, worsening, or stability comparing neuropsychological tests raw measurements to the standard deviation of the control group (the population sample). The second method (b) classified improvement or worsening according to any change on the classification of memory based on the Z-score. This score was calculated based on raw neuropsychological clinical measurements, the mean of the control (population's sample of Curitiba) for the cognitive test, and the standard deviation (SD) of the control. We then classified each patient, both at the pre and postoperative periods, as having normal memory (Z-score greater than -1.26) or deficits (mild, Z-score ranging from -1.6 to -1.26; moderate, from -2.2 to -1.6; or severe, less than -2.2$)^{10}$.

\section{RESULTS}

\section{Neuropsychological outcome}

In pursuance of a broad overview, we compared memory performances of all patients before and after surgery (using the Z-score classification), regardless of the surgical technique. We found that in terms of verbal memory, $17.9 \%$ of patients improved, $23.9 \%$ worsened, and $58.2 \%$ had no change. In respect of visual memory, $16.7 \%$ improved, $10.6 \%$ worsened, and $72.7 \%$ had no change. In the following paragraphs, the results on more detailed analyses are shown.

Conforming to the first analytic method (a), there were no differences in the evolution of neuropsychological performance, in regards to both visuospatial memory $(p=0.182)$ and verbal memory $(p=0.386)$, for the two surgical approaches. Similarly, no differences were found in regards to the side operated on (Table 2).

We essentially found the same results when using the analytic method (b). Considering the time points prior and
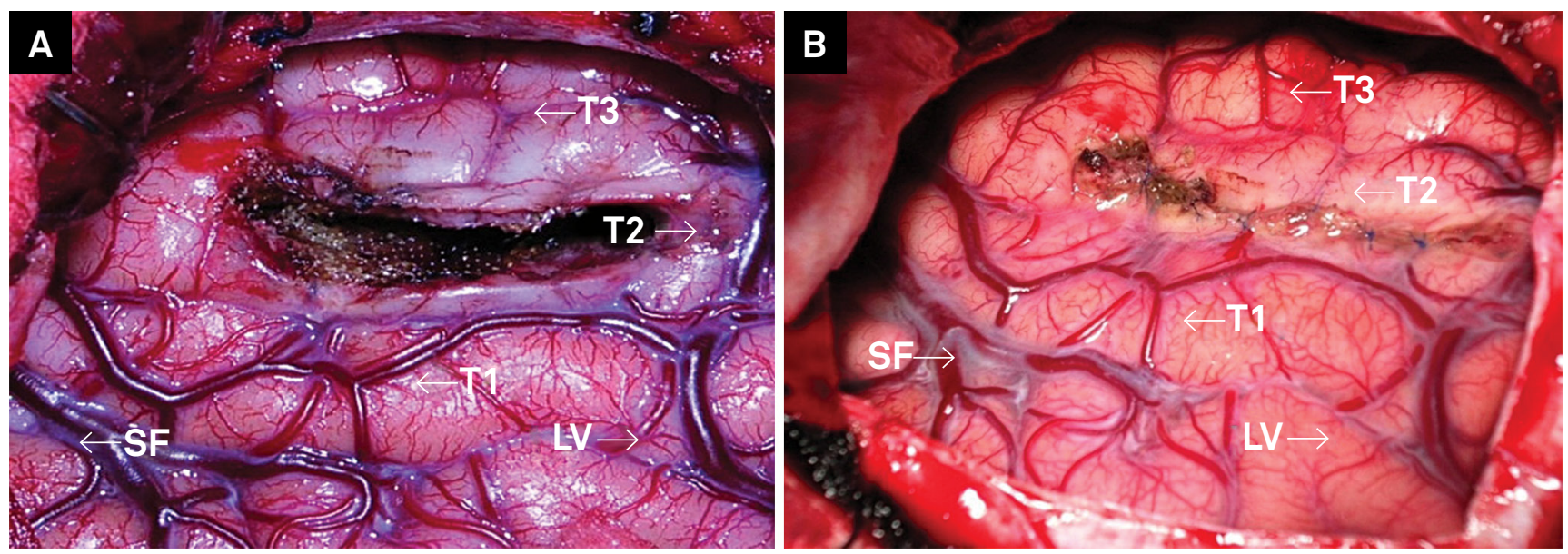

(A) Final surgical cavity, after resection and hemostasis. (B) View after suture of the cortical incision. SelAH: selective amygdalohippocampectomy; SF: Sylvian fissure; LV: Labbé vein.

Figure 4. SelAH, operative site. 
after surgery, there were no differences in the distribution of categories both in terms of visual memory $(p=0.117)$, and of verbal memory ( $p=0.817$ ). Of note, in the ATL group, when looking exclusively at the tests done prior to operation, less patients had visual memory classified as normal in relation to the SelAH group $(\mathrm{p}=0.027)$. However, as shown above, considering the evolution before and after surgery, this observation did not result in differences for either group (Tables 3 and 4).

Further, analyses were done separately for the dominant and the nondominant subsets. Focusing on the ATL

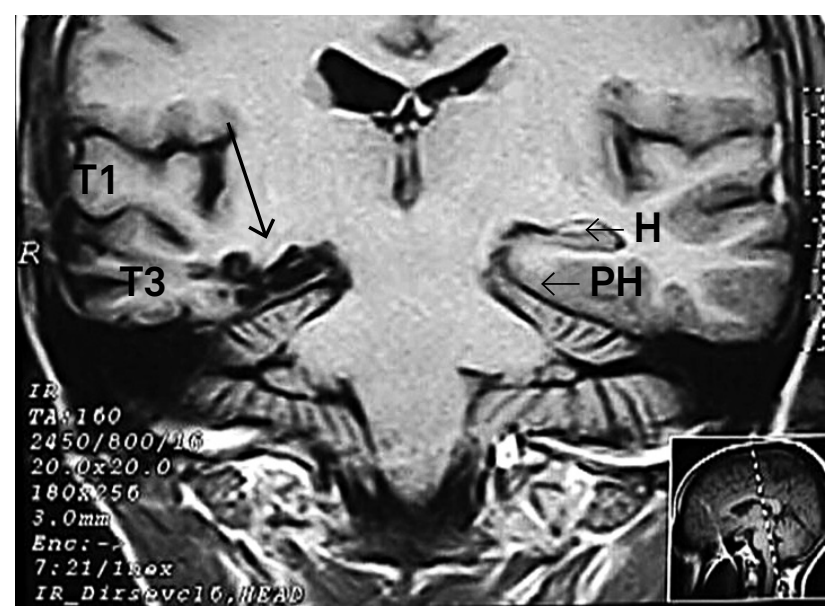

T1-weighted coronal MRI. MRI coronal T1 sequence. Black arrow targets the site of status-post right SelAH, mesial structures were appropriately resected; SelAH: selective amygdalohippocampectomy; $\mathrm{H}$ : hippocampus; $\mathrm{PH}$ : parahippocampal gyrus.

Figure 5. SelAH, postoperative MRI. group, specifically the individuals operated on the dominant hemisphere, 60 percent of them had normal verbal memory preoperatively; this figure dropped to 20 percent after surgery. Still concerning the ATL on the dominant side, 20 percent of patients had severe verbal memory deficit prior to the ATL; after the procedure, $53.3 \%$ of patients were assessed as having severe verbal memory deficit. In regards to individuals who underwent ATL on the nondominant hemisphere, the verbal memory persisted the same without relevant change. Finally, in the whole ATL group, including dominant and nondominant, the visuospatial memory remained with no alteration throughout (Table 3).

When focusing on the SelAH group, on the other hand, there was no important difference in regards to evolution of cognitive status (including both verbal and visuospatial memories) - regardless of the side of operation (dominant versus nondominant) (Table 4).

After interpreting all these data and results, it was concluded that the only subgroup of patients that experienced a relevant cognitive deficit after surgery was the set of subjects who underwent ATL on the dominant hemisphere. Postoperatively, these patients showed an important decline in cognition, exclusively in verbal memory.

\section{Seizure outcome}

The evaluation of postoperative mid/long-term seizure control was done based on the Engel rating scale ${ }^{11}$, which is the most commonly used outcome classification for epilepsy surgery patients ${ }^{12}$. This evaluation occurred, for every

Table 2. Comparison of longitudinal change (pre and postoperative) in neuropsychological performance, between ATL and SelAH groups, using standard deviation variation.

\begin{tabular}{|c|c|c|c|c|c|c|c|c|}
\hline & \multicolumn{2}{|c|}{ Verbal memory } & \multicolumn{2}{|c|}{ Visuospatial memory } & \multicolumn{2}{|c|}{ Verbal memory } & \multicolumn{2}{|c|}{ Verbal memory } \\
\hline & SelAH n (\%) & ATL n (\%) & SelAH n (\%) & ATL n (\%) & ND side $n(\%)$ & Dom side $\mathrm{n}(\%)$ & ND side $n(\%)$ & Dom side $\mathrm{n}(\%)$ \\
\hline Improvement & $7(20.6)$ & $5(15.2)$ & $4(12.1)$ & $8(24.2)$ & $7(21.2)$ & $5(14.7)$ & $5(15.2)$ & $7(20.6)$ \\
\hline Worsening & $9(26.5)$ & $14(42.4)$ & $2(6.1)$ & 0 & $11(33.3)$ & $12(35.3)$ & 0 & $2(5.9)$ \\
\hline Stability & $18(52.9)$ & $14(42.4)$ & $27(81.8)$ & $25(75.8)$ & $15(45.5)$ & $17(50.0)$ & $28(84.8)$ & $25(73.5)$ \\
\hline Total & 34 & 33 & 33 & 33 & 33 & 34 & 33 & 34 \\
\hline$p$-value & \multicolumn{2}{|c|}{0.386} & \multicolumn{2}{|c|}{0.182} & \multicolumn{2}{|c|}{0.784} & \multicolumn{2}{|c|}{ Not applicable } \\
\hline
\end{tabular}

SelAH: selective amygdalohippocampectomy; ATL: anterior temporal lobectomy; Dom: Dominant; ND: Nondominant; n: number of patients. Note: Chi-square tests were applied.

Table 3. Comparison of side of operation (dominant vs. nondominant) in the ATL group in relation to longitudinal change (pre and postoperative) in neuropsychological performance using Z-score for classification.

\begin{tabular}{|c|c|c|c|c|c|c|c|c|}
\hline \multirow{3}{*}{ ATL } & \multicolumn{4}{|c|}{ Verbal memory } & \multicolumn{4}{|c|}{ Visuospatial memory } \\
\hline & \multicolumn{2}{|c|}{ Pre } & \multicolumn{2}{|c|}{ Post } & \multicolumn{2}{|c|}{ Pre } & \multicolumn{2}{|c|}{ Post } \\
\hline & ND n (\%) & Dom n (\%) & ND n (\%) & Dom n (\%) & ND n (\%) & Dom n (\%) & ND n (\%) & Dom n (\%) \\
\hline Normal & $11(61.11)$ & $9(60.00)$ & $14(77.78)$ & $3(20.00)$ & $13(72.22)$ & $9(60.00)$ & 15 (83.33) & $11(73.33)$ \\
\hline Mild & $2(11.11)$ & $2(13.33)$ & $1(5.56)$ & $1(6.67)$ & $3(16.67)$ & $2(13.33)$ & $2(11.11)$ & $2(13.33)$ \\
\hline Moderate & $2(11.11)$ & $1(6.67)$ & $1(5.56)$ & $3(20.00)$ & $2(11.11)$ & $4(26.67)$ & $1(5.56)$ & $2(13.33)$ \\
\hline Severe & $3(16.67)$ & $3(20.00)$ & $2(11.11)$ & $8(53.33)$ & & & & \\
\hline Total & 18 & 15 & 18 & 15 & 18 & 15 & 18 & 15 \\
\hline
\end{tabular}

ATL: anterior temporal lobectomy; Dom: Dominant; ND: Nondominant; n: number of patients. Note: Chi-square tests were applied. Mild, moderate and severe refer to degrees of memories deficits. 
patient, at the $6^{\text {th }}$ month after procedure, then annually up until the last clinical visit.

Table 5 shows, by percentage, the Engel rate at each evaluation for every patient in the study. Further, we categorized Engel rates I and II as 'satisfactory', and plotted the percentage of patients (from both groups, side to side) fitting the 'satisfactory' category, at the different clinical evaluations (Table 6). Regardless of the surgical approach, the number of patients who were rated Engel I or II was persistently higher than $70 \%$ throughout the 5-year period.

After a mean follow-up of 64 months, $82 \%$ of all patients had a satisfactory (Engel I or II) outcome, and $51.18 \%$ remained seizure-free (Engel Ia) throughout the first 5 years after procedure. In spite of the fact that seizure-freedom (Engel Ia) seemed to be reached more rapidly after SelAH than ATL during the first years after surgery, when we look at the entire follow-up of 5 years there are no statistically significant differences between the two groups.

\section{Complications}

Table 7 summarizes our descriptive classification (major or minor) of all surgical complications, and also distinguishes which of them resulted in neurological deficits (classified as being transitory or permanent).

Overall, 19 patients (15 ATL; 4 SelAH), or $28.35 \%$, developed general complication(s) after surgery. There was not any death. In the SelAH group, there were two major and two minor complications; also in this set of patients, six developed postoperative neurological deficits, only one being permanent. In contrast, in the ATL group, there were 13 major and two minor complications; neurological deficits were nine, two being permanent. Comparing the major complications between the two techniques, rates are higher in the ATL group ( $p=0.004)$. In regards to complications resulting in neurological deficits, there was no significant difference between the both approaches $(p=0.370)$. Besides complications, we believe that patient satisfaction is also important

Table 4. Comparison of side of operation (dominant vs. nondominant) in the SelAH group in relation to longitudinal change (pre and postoperative) in neuropsychological performance using Z-score for classification.

\begin{tabular}{|c|c|c|c|c|c|c|c|c|}
\hline \multirow{3}{*}{ SelAH } & \multicolumn{4}{|c|}{ Verbal memory } & \multicolumn{4}{|c|}{ Visuospatial memory } \\
\hline & \multicolumn{2}{|c|}{ Pre } & \multicolumn{2}{|c|}{ Post } & \multicolumn{2}{|c|}{ Pre } & \multicolumn{2}{|c|}{ Post } \\
\hline & ND n (\%) & Dom n (\%) & ND n (\%) & Dom n (\%) & ND n (\%) & Dom n (\%) & ND n (\%) & Dom n (\%) \\
\hline Normal & $13(86.67)$ & $8(42.11)$ & $9(60.00)$ & $12(63.16)$ & $12(85.71)$ & $18(94.74)$ & $12(85.71)$ & $18(94.74)$ \\
\hline Mild & $1(6.67)$ & $1(5.26)$ & $0(0.00)$ & $1(5.26)$ & & & & \\
\hline Moderate & $0(0.00)$ & $2(10.53)$ & $2(13.33)$ & $1(5.26)$ & $2(14.29)$ & $1(5.26)$ & $2(14.29)$ & $1(5.26)$ \\
\hline Severe & $1(6.67)$ & $8(42.11)$ & $4(26.67)$ & $5(26.32)$ & & & & \\
\hline
\end{tabular}

$\begin{array}{llllllll}\text { Total } & 15 & 19 & 15 & 19 & 14 & 19 & 14\end{array}$

SelAH: selective amygdalohippocampectomy; Dom: Dominant; ND: Nondominant; n: number of patients. Note: Chi-square tests were applied. Mild, moderate and severe refer to degrees of memories deficits.

Table 5. Postoperative seizure outcome, according to Engel's classification, at predetermined time points.

\begin{tabular}{|c|c|c|c|c|c|c|c|c|c|c|c|c|}
\hline \multirow{2}{*}{ Engel } & \multicolumn{2}{|c|}{6 months } & \multicolumn{2}{|c|}{1 year } & \multicolumn{2}{|c|}{2 years } & \multicolumn{2}{|c|}{3 years } & \multicolumn{2}{|c|}{4 years } & \multicolumn{2}{|c|}{5 years } \\
\hline & SelAH & ATL & SelAH & ATL & SelAH & ATL & SelAH & ATL & SelAH & ATL & SelAH & ATL \\
\hline la & 85.29 & 72.72 & 64.7 & 54.54 & 58.82 & 54.54 & 59.37 & 51.51 & 44.44 & 51.51 & 47.82 & 54.54 \\
\hline $\mathrm{Ib}$ & 8.82 & 15.15 & 8.82 & 15.15 & 8.82 & 6.06 & 6.25 & 6.06 & 7.4 & 9.09 & 13.04 & 4.54 \\
\hline IC & - & - & - & - & 5.88 & 3.03 & 6.25 & 3.03 & 11.11 & 6.06 & 4.34 & 4.54 \\
\hline Id & - & - & 14.7 & 6.06 & 8.82 & 9.09 & 12.5 & 6.06 & 11.11 & - & 8.69 & - \\
\hline $\mathrm{Ila}$ & - & - & 8.82 & 12.12 & 14.7 & 9.09 & 6.25 & 9.09 & 11.11 & 6.06 & 13.04 & 4.54 \\
\hline $11 \mathrm{~b}$ & - & 6.06 & - & 6.06 & - & 3.03 & - & - & - & - & - & - \\
\hline IIc & - & - & - & - & - & - & 3.12 & 3.03 & 7.4 & 3.03 & 4.34 & 4.54 \\
\hline Ild & 2.94 & - & - & - & - & - & - & - & - & - & - & - \\
\hline IIla & 2.94 & 6.06 & 2.94 & 6.06 & 2.94 & 12.12 & 3.12 & 15.15 & 3.7 & 12.12 & 4.34 & 9.09 \\
\hline IIlb & - & - & - & - & - & - & 3.12 & 3.03 & 3.7 & 3.03 & 4.34 & 4.54 \\
\hline $\mathrm{IVa}$ & - & - & - & - & - & 3.03 & - & 3.03 & - & 9.09 & - & 13.63 \\
\hline $\mathrm{IVb}$ & - & - & - & - & - & - & - & - & - & - & - & - \\
\hline IVc & - & - & - & - & - & - & - & - & - & - & - & - \\
\hline$n$ & 34 & 33 & 34 & 33 & 34 & 33 & 32 & 33 & 27 & 33 & 23 & 22 \\
\hline Median Classification & la & la & la & la & la & la & la & la & $\mathrm{lb}$ & la & $\mathrm{lb}$ & la \\
\hline Minimum Classification & la & la & la & la & la & la & la & la & la & la & la & la \\
\hline Maximum Classification & IIIa & IIla & IIIa & IIla & IIIa & $\mathrm{IVa}$ & $\| l l b$ & $\mathrm{IVa}$ & IIIb & $\mathrm{IVa}$ & IIIb & $\mathrm{IVa}$ \\
\hline p-value & \multicolumn{2}{|c|}{0.379} & \multicolumn{2}{|c|}{0.393} & \multicolumn{2}{|c|}{0.473} & \multicolumn{2}{|c|}{0.331} & \multicolumn{2}{|c|}{0.965} & \multicolumn{2}{|c|}{0.761} \\
\hline
\end{tabular}

SelAH: selective amygdalohippocampectomy; ATL: anterior temporal lobectomy. Statistical analysis performed with the Mann-Whitney test; $\mathrm{p}<0.05$. Engel classes were considered as ordinal scales variables (points) ranging from 1 point (for Class la) to 13 points (for Class IVc). The numbers refer to the percentage of patients scored in each subgroup in Engel's Classification (ENGEL et al, 1993). 
Table 6. Comparison of postoperative seizure control between ATL and SelAH groups according to satisfactory (Engel I and II) or unsatisfactory (Engel III and IV) categories at predetermined time points.

\begin{tabular}{|c|c|c|c|c|c|c|}
\hline \multirow{2}{*}{ Assessment } & \multirow{2}{*}{ Engel } & \multicolumn{2}{|c|}{ SelAH } & \multicolumn{2}{|c|}{ ATL } & \multirow[t]{2}{*}{$p$-value } \\
\hline & & $\mathrm{n}$ & $\%$ & $\mathrm{n}$ & $\%$ & \\
\hline \multirow[t]{3}{*}{6 months } & Satisfactory & 33 & 97.1 & 31 & 93.9 & 0.613 \\
\hline & Unsatisfactory & 1 & 2.9 & 2 & 6.1 & \\
\hline & Total & 34 & 100.0 & 33 & 100.0 & \\
\hline \multirow[t]{3}{*}{1 year } & Satisfactory & 33 & 97.1 & 31 & 93.9 & 0.613 \\
\hline & Unsatisfactory & 1 & 2.9 & 2 & 6.1 & \\
\hline & Total & 34 & 100.0 & 33 & 100.0 & \\
\hline \multirow[t]{3}{*}{2 years } & Satisfactory & 33 & 97.1 & 28 & 84.8 & 0.105 \\
\hline & Unsatisfactory & 1 & 2.9 & 5 & 15.2 & \\
\hline & Total & 34 & 100.0 & 33 & 100.0 & \\
\hline \multirow[t]{3}{*}{3 years } & Satisfactory & 32 & 100.0 & 33 & 100.0 & 1 \\
\hline & Unsatisfactory & 0 & 0.0 & 0 & 0.0 & \\
\hline & Total & 32 & 100.0 & 33 & 100.0 & \\
\hline \multirow[t]{3}{*}{4 years } & Satisfactory & 25 & 92.6 & 25 & 75.8 & 0.162 \\
\hline & Unsatisfactory & 2 & 7.4 & 8 & 24.2 & \\
\hline & Total & 27 & 100.0 & 33 & 100.0 & \\
\hline \multirow[t]{3}{*}{5 years } & Satisfactory & 21 & 91.3 & 16 & 72.7 & 0.135 \\
\hline & Unsatisfactory & 2 & 8.7 & 6 & 27.3 & \\
\hline & Total & 23 & 100.0 & 22 & 100.0 & \\
\hline
\end{tabular}

SelAH: selective amygdalohippocampectomy; ATL: anterior temporal lobectomy; n: number of patients. Chi-square tests were applied. Engel's Classification (ENGEL et al. 1993). to consider. For that, we collected patients' perception after procedure: 61 of the 67 patients $(91 \%)$ were satisfied, and would undergo surgery again, if necessary.

\section{DISCUSSION}

The aim of this study was to compare the results of two techniques, ATL or SelAH, for patients diagnosed with medically refractory mesial TLE secondary to unilateral MTS, without any additional structural lesion. Quite a few studies have tried to identify the best surgical technique to treat patients with TLE, few of them, however, included patients with unilateral MTS as the sole underlying pathology ${ }^{13,14,15}$. With this goal, we carefully selected a series of patients diagnosed with unilateral MTS who were operated by one of our two attending neurosurgeons. Although there was no randomization per $s e$, both groups were epidemiologically homogenous on most variables. Final data analysis was divided in three spheres: seizure outcome, cognitive outcome, and complications.

Concerning seizure outcomes, no statistically significant differences in seizure outcomes after ATL and SelAH were observed in our study. It has been described by most major series that postoperative seizure control does not differ significantly between the two approaches ${ }^{7,13,14,15,16,17,18,19,20,21}$.

Table 7. Operative complications according to surgical approach.

\begin{tabular}{|c|c|c|c|}
\hline Complications & SelAH $(n / N)$ & ATL $(n / N)$ & Total \\
\hline \multirow[t]{4}{*}{ Operative site infection / Meningitis } & - 1 Operative site infection & - 3 Meningitis & $8 / 67$ \\
\hline & -1 Abscesses & -2 Abscesses & \\
\hline & & - 1 Empyema + osteomyelitis & \\
\hline & $2 / 34$ & $6 / 33$ & \\
\hline \multirow[t]{3}{*}{ Hemorrhage and/or Hematoma } & & - 1 Cerebellar hemorrhage & $2 / 67$ \\
\hline & & - 1 Operative site hematoma & \\
\hline & 0 & $2 / 33$ & \\
\hline \multirow[t]{3}{*}{ Cerebrospinal fluid (CSF) related } & -1 CSF leak & -2 CSF leaks & $4 / 67$ \\
\hline & & - 1 Subdural hygroma & \\
\hline & $1 / 34$ & $3 / 33$ & \\
\hline \multirow[t]{4}{*}{$\begin{array}{l}\text { Ischemic cerebrovascular accident } \\
\text { (iCVA) }\end{array}$} & $\begin{array}{l}-1 \text { iCVA affecting left internal } \\
\text { capsule = permanent hemiparesis }\end{array}$ & - 1 Left, transitory MCA ischemia (vasospasm) & $4 / 67$ \\
\hline & & - 1 Ischemia in the left MCA territory = permanent deficits & \\
\hline & & $\begin{array}{l}-1 \text { Ischemia in the right MCA territory due to } \\
\text { edema }=\text { hemiparesis }\end{array}$ & \\
\hline & $1 / 34$ & $3 / 33$ & \\
\hline \multirow[t]{6}{*}{ Neurological deficit } & - 3 III CN palsies & -4 III CN palsies & $15 / 67$ \\
\hline & - 2 Transitory dysnomias & - 2 Transitory dysphagias & \\
\hline & - 1 Permanent hemiplegia & - 1 Transitory hemiparesis & \\
\hline & & - 1 Permanent hemiparesis & \\
\hline & & - 1 Permanent hemiplegia & \\
\hline & $6 / 34$ & $9 / 33$ & \\
\hline Transitory & 5 & 7 & $12 / 67$ \\
\hline \multirow[t]{2}{*}{ permanent } & 1 & 2 & $3 / 67$ \\
\hline & 0 & - 1 Ventilator-associated pneumonia & $1 / 67$ \\
\hline Systemic infection & & $1 / 33$ & \\
\hline
\end{tabular}

SelAH: selective amygdalohippocampectomy; ATL: anterior temporal lobectomy; n: number of complications; N: number of patients submitted to surgical approach; MCA: middle cerebral artery; CN: cranial nerve. 
Nonetheless, three studies have found better seizure-control in patients submitted to ATL ${ }^{4,22,23}$. Similarly, two recent systematic reviews concluded that ATL is associated with a reduced rate of seizure recurrence compared to SelAH ${ }^{24,25}$.

In other words, a consensus on this matter has not yet been reached. There are a number of reasons that contribute to this lack of agreement. Few studies performed to date have aimed to compare seizure control after ATL and SelAH at one single center, due to the fact surgical programs generally choose one of these approaches to be used. Hence, comparisons can only be done with the collaboration of at least two centers. Further, ATL and SelAH groups usually have unequal number of patients. Also an issue, follow-up periods are frequently of just a couple of years ${ }^{4,18}$. Finally, most studies include individuals with TLE due to several different pathologies, such as tumors, malformations of cortical development, MTS, etc.; rarely do studies limit the recruitment to patients with MTS as the only epileptogenic source ${ }^{18}$. All these observations help create many potential biases, which ultimately weaken methodology strength ${ }^{14}$.

Along these lines, our study tried to minimize all these potential methodological pitfalls. All operations were performed at the same center, where ATL and SelAh were alternated every week. We carefully recruited similar number of patients for both groups. These individuals had similar clinical presentation, unilateral MTS on MRI without additional lesions, unilateral epileptiform discharges on EEG, and were homogenous on epidemiological variables. Further, our mean follow-up was more than 5 years, which is long compared to the majority of studies in this field.

Regarding neuropsychological outcomes, our study did not observe statistically significant differences between the two surgical approaches. However, we did note slight superiority on postoperative verbal memory in patients submitted to SelAH. Based on our analysis, the most important predictor of worse postoperative cognitive status was surgery on the dominant hemisphere, regardless of the technique.

As with seizure control, there is not yet a consensus in terms of cognitive outcomes after ATL and SelAH. Numerous studies concluded that there are no differences between the two approaches, including the systematic review conducted by Hu et al. ${ }^{16,25,26}$. Nevertheless, many other studies claim that SelAH confers lower cognitive morbidity, mostly involving language and verbal memory. In fact, many of these studies agree that ATL is particularly cognitively harmful when performed on the dominant hemisphere $e^{6,7,23,27,28,29}$ - an observation that was also noted in our series.
In terms of operative complications, we found a high rate of general complications. This high rate resulted essentially from major complications, especially in the ATL group. In fact, there was a statistically significant difference in major complications between the ATL and SelAH groups. We could not find published studies that specifically compared operative complications between ATL and SelAH, therefore our subgroup data could not be compared to other centers' results. However, in comparison to complications in epilepsy surgery in general (including different approaches to resective surgery, and invasive EEG implantation), our rate of total complications is categorically higher ${ }^{8}$. Notably, despite the relatively high overall complication rate, $91 \%$ of all operated patients were satisfied with having had epilepsy surgery and would undergo it again if necessary. This high satisfaction rate in our patients after epilepsy surgery is in agreement with other recent studies ${ }^{30}$. This finding reinforces the importance of surgical therapy in epilepsy - when well indicated.

We believe at least three reasons could address our incidence of operative complications. First, given that our center is a teaching-hospital, residents' learning curve could have potentially affected the complication rate. Also, all patients needed to be followed for at least 2 years after surgery and have their charts thoroughly completed. As a result, these criteria could have selected a biased sample of patients who needed closer follow-up and care. Thirdly, there is a possibility that operative complications are under reported both in charts and in the literature.

We acknowledge that this study has limitations, basically because it is retrospective, and the number of enrolled patients is small. Another limitation lies in the fact that we incorporated data from the experience of two surgeons (one of them systematically performing ATL and the other SelAH); thus, the experience and skills of each surgeon should be taken into consideration when interpreting our study results. Nonetheless, although individual studies may not have enough power to detect differences that are statistically and clinically significant, these investigations are necessary and essential to produce reliable and important significant medical evidence when analysed on a broad perspective.

\section{Acknowledgements}

The authors gratefully acknowledge Ms. Yvonne DeWit for proofreading the manuscript.
1. Junna MR, Buechler R, Cohen-Gadol AA, Mandrekar J, Christianson T, Marsh WR et al. Prognostic importance of risk factors for temporal lobe epilepsy in patients undergoing surgical treatment. Mayo Clinic Proc. 2013;88(4):332-36. doi:10.1016/j.mayocp.2013.01.011
2. Kwan P, Arzimanoglou A, Berg AT, Brodie MJ, Allen Hauser W, Mathern $G$ et al. Definition of drug resistant epilepsy: consensus proposal by the ad hoc Task Force of the ILAE Commission of Therapeutic Strategies. Epilepsia. 2010;51(6):1069-77. 
3. Ramey WL, Martirosyan NL, Lieu CM, Hasham HA, Lemole GM $\mathrm{Jr}$, Weinand ME. Current management and surgical outcomes of medically intractable epilepsy. Clin Neurol Neurosurg. 2013;115(12):2411-8. doi:10.1016/j.clineuro.2013.09.035

4. Bate H, Eldridge P, Varma T, Wieshmann UC. The seizure outcome after amygdalohippocampectomy and temporal lobectomy. Eur J Neurol. 2007;14(1):90-4. doi:10.1111/j.1468-1331.2006.01565.x

5. Gilliam F, Hecimovic H, Sheline Y. Psychiatric comorbidity, health, and function in epilepsy. Epilepsy Behav. 2003;4 Suppl 4:26-30. doi:10.1016/j.yebeh.2003.10.003

6. Helmstaedter C, Reuber M, Elger CC. Interaction of cognitive aging and memory deficits related to epilepsy surgery. Ann Neurol. 2002;52(1):89-94. doi:10.1002/ana.10260

7. Paglioli E, Palmini A, Portuguez M, et al. Seizure and memory outcome following temporal lobe surgery: selective compared with nonselective approaches for hippocampal sclerosis. J Neurosurg. 2006;104(1):70-8. doi:10.3171/jns.2006.104.1.70

8. Hader WJ, Tellez-Zenteno J, Metcalfe A, et al. Complications of epilepsy surgery: A systematic review of focal surgical resections and invasive EEG monitoring. Epilepsia. 2013;54(5):840-7. doi:10.1111/epi.12161

9. Salanova V, Markand O, Worth R. Temporal lobe epilepsy surgery: outcome, complications, and late mortality rate in 215 patients. Epilepsia. 2002;43(2):170-4. doi:10.1046/j.1528-1157.2002.33800.x

10. Strauss E, Sherman EMS, Spreen O. Compendium of neuropsychological tests: administration, norms and commentary. 3rd ed. New York: Oxford University Press; 2006.

11. Engel J Jr, Van Ness PC, Rasmussen T. Outcome with respect to epileptic seizures. In: Engel J Jr, editor. Surgical treatment of the epilepsies. New York: Raven; 1993. p. 609-21.

12. Schomer DL, Black PM. A 24-year-old woman with intractable seizures: review of surgery for epilepsy. JAMA. 2008;3;300(21):2527-38. doi:10.1001/jama.2008.709

13. Tanriverdi T, Olivier A. Cognitive changes after unilateral cortico-amygdalohippocampectomy unilateral selective-amygdalohippoca mpectomy mesial temporal lobe epilepsy. Turk Neurosurg. 2007;17(2):91-9.

14. Tanriverdi T, Olivier A, Poulin N, Andermann F, Dubeau F. Long-term seizure outcome after mesial temporal lobe epilepsy surgery: corticalamygdalohippocampectomy versus selective amygdalohippocampectomy. J Neurosurg. 2008;108(3):517-24. doi:10.3171/JNS/2008/108/3/0517

15. Wendling AS, Hirsch E, Wisniewski I, Davanture C, Ofer I, Zentner $J$ et al. Selective amygdalohippocampectomy versus standard temporal lobectomy in patients with mesial temporal lobe epilepsy and unilateral hippocampal sclerosis. Epilepsy Res. 2013;104(1-2):94-104. doi:10.1016/j.eplepsyres.2012.09.007

16. Tanriverdi T, Dudley RW, Hasan A, Al Jishi A, Al Hinai Q, Poulin $\mathrm{N}$ et al. Memory outcome after temporal lobe epilepsy surgery: corticoamygdalohippocampectomy versus selective amygdalohippocampectomy. J Neurosurg. 2010;113(6):1164-75. doi:10.3171/2009.10.JNS09677

17. Yang XL, Lu QC, Xu JW, Wang GS, Liu Q. Predictors of outcome in the surgical treatment for epilepsy. Chin Med J (Eng). 2011;124(24):4166-71.

18. Arruda F, Cendes F, Andermann F, Dubeau F, Villemure JG, Jones-Gotman $\mathrm{M}$ et al. Mesial atrophy and outcome after amygdalohippocampectomy or temporal lobe removal. Ann Neurol. 1996;40(3):446-50. doi:10.1002/ana.410400314

19. Lee T, Mackenzie RA, Walker AJ, Matheson JM, Sachdev P. Effects of left temporal lobectomy and amygdalohippocampectomy on memory. J Clin Neurosci. 1997;4(3):314-9. doi:10.1016/S0967-5868(97)90098-9

20. Morino M, Uda T, Naito K, Yoshimura M, Ishibashi K, Goto T et al. Comparison of neuropsychological outcomes after selective amygdalohippocampectomy versus anterior temporal lobectomy. Epilepsy Behav. 2006;9(1):95-100. doi:10.1016/j.yebeh.2006.04.017

21. Grivas A, Schramm J, Kral T, Lehe M, Helmstaedter C, Elger CE et al. Surgical treatment for refractory temporal lobe epilepsy in the elderly: seizure outcome and neuropsychological sequels compared with a younger cohort. Epilepsia. 2006;47(8):1364-72. doi:10.1111/j.1528-1167.2006.00608.x

22. Mackenzie RA, Matheson J, Ellis M, Klamus J. Selective versus non-selective temporal lobe surgery for epilepsy. J Clin Neurosci. 1997;4(2):152-4. doi:10.1016/S0967-5868(97)90064-3

23. Clusmann H, Kral T, Fackeldey E, Blümcke I, Heimstaedter C, Oertzen $\mathrm{J}$ et al. Lesional mesial temporal lobe epilepsy and limited resections: prognostic factors and outcome. J Neurol Neurosurg Psychiatry. 2004;75(11):1589-96. doi:10.1136/jnnp.2003.024208

24. Josephson CB, Dykeman J, Fiest KM, Liu X, Sadler RM, Jette N et al. Systematic review and meta-analysis of standard vs selective temporal lobe epilepsy surgery. Neurology. 2013;80(18):1669-76. doi:10.1212/WNL.0b013e3182904f82

25. Hu WH, Zhang C, Zhang K, Meng FG, Chen N, Zhang JG. Selective amygdalohippocampectomy versus anterior temporal lobectomy in the management of mesial temporal lobe epilepsy: a meta-analysis of comparative studies: a systematic review. J Neurosurg. 2013;119(5):1089-97. doi:10.3171/2013.8.JNS121854

26. Mansouri A, Fallah A, McAndrews MP, Cohn M, Mayor D, Andrade D et al. Neurocognitive and seizure outcomes of selective amygdalohippocampectomy versus anterior temporal lobectomy for mesial temporal lobe epilepsy. Epilepsy Res Treat. 2014;2014:ID 306382. doi:10.1155/2014/306382

27. Helmstaedter C, Grunwald T, Lehnertz K, Gleißner U, Elger CE. Differential involvement of left temporolateral and temporomesial structures in verbal declarative learning and memory: evidence from temporal lobe epilepsy. Brain Cogn. 1997;35(1):110-31. doi:10.1006/brcg.1997.0930

28. Helmstaedter C, Richter S, Roske S, Oltmanns F, Schramm J, Lehmann TN. Differential effects of temporal pole resection with amygdalohippocampectomy versus selective amygdalohippocampectomy on material-specific memory in patients with mesial temporal lobe epilepsy. Epilepsia. 2008;49(1):88-97. doi:10.1111/j.1528-1167.2007.01386.x

29. Kneebone AC, Lee GP, Wade LT, Loring DW. Rey Complex Figure: figural and spatial memory before and after temporal lobectomy for intractable epilepsy. J Int Neuropsychol Soc. 2007;13(4):664-71. doi:10.1017/S1355617707070828

30. Taft C, Sager Magnusson E, Ekstedt G, Malmgren K. Health-related quality of life, mood, and patient satisfaction after epilepsy surgery in Sweden: a prospective controlled observational study. Epilepsia. 2014;55(6):878-85. doi:10.1111/epi.12616 